\title{
Does Psychological Ownership of Knowledge Matter? Servant Leadership and Knowledge Hiding in Organizations: AProposed Framework
}

\author{
Gabriel Oyebanjo OGUNLELA \\ Mangosuthu University of Technology \\ Faculty of Management Science, Umlazi, Durban. South Africa \\ ogunlela.gabriel@mut.ac.za
}

\begin{abstract}
Knowledge hiding can have many adverse effects on organizational development, and it is consequently important to look at its various causes, and also the impact such activities haveon targets, perpetrators, and organizations as a whole. Various studies investigate the effects of knowledge hiding on organizations, and the employees surveyed in these studies have identified some of the possible drivers of knowledge hiding to be: a lack of employee trust; poor employee incentives; employee retaliation; employee insecurity; the intentional withholding of knowledge; the workplace environment; a craving for competitive advantage over fellow staff members; and also, feelings of psychological ownership. This paper investigates the influence of servant leadership on knowledge hiding, and proposes a mediating variable: that of the influence of psychological ownership of knowledge on the relationship between servant leadership and knowledge hiding attitudes in staff within organizations. A model is therefore proposed to achieve this, since it could be argued that increased servant leadership, through the psychological ownership of knowledge, can have a positive effect on staff attitudes towards knowledge hiding, and can also be used to encourage them to share knowledge to improve their overall performances, and the competitive advantages of organizations. The proposed model can also be used to assist managers in developing strategies for motivating staff to become more committed to the visions of organizations, in order to improve the performances of both themselves and their organizations overall.
\end{abstract}

Keywords: Servant leadership, knowledge hiding, psychological ownership of knowledge, mediating, performance

\section{Introduction}

Knowledge management has recently gained wide attention globally due to its impact on organizational competitiveness (Algere, Sengupta, \& Lapiedra, 2011); (Emadzade, Mashayekhi, \& Abdar, 2012). According to The Business Dictionary (2017), knowledge management is comprised of "strategies and processes designed to identify, capture, structure, value, leverage, and share an organization's intellectual assets to enhance its performance and competitiveness based on two critical activities: (1) capture and documentation of individual explicit and tacit knowledge, and (2) its dissemination within the organization". Knowledge management is defined by Davenport and Prusak (1998) as "a fluid mix of framed experience, values, contextual information and expert insights that provides a framework for evaluating and incorporating new experience and information". Furthermore, knowledge management is the creation, identification, collection, organizing, sharing, adaptation and use of internal knowledge and best practices. Attention is frequently drawn to the positive advantages organizations are able to gain from effective knowledge management (Liang, You, \& Liu, 2010). Less attention has, however, been paid to the possible negative impactswhich knowledge hiding, or the withholding of knowledge, can have on companies (Peng, 2013); (Connelly, Zweig, Webster, \& Trougakos, 2003).

Servant leadership has long been practiced in the African context, and is confirmed asbeing effective in communities where it has been adopted (Mibigi \& Maree, 1995). Nelson (2003) promotes the model for servant leadership theory proposed by Patterson (2003), which focuses on how servant leaders perform within their organizations, to confirm whether this impacts positively on the performance of both staff and of organizations themselves. It is, hence, argued that servant leadership can exerta positive influenceon the overall performance of organizations. The intention of this paper is to extend the discussion on the subject of how a particular leadership style can assist staff to desist from knowledge hiding through the adoption of servant leadership. Using the premise of psychological ownership of knowledge as a mediating factor between knowledge hiding and servant leadership, a framework can be proposed and tested. This is 
important in being able to ascertain whether servant leadership truly encourages staff to abstain from knowledge hiding attitudes. Identifying psychological knowledge ownership in employees as a mediating mechanism could, in addition, improve upon a rational understanding of the influenceof servant leadership on employeeknowledge hiding behaviors, and also assist management in developing and embracing useful management interventions to improve their overall organizational performance.

\section{Literature Review}

Knowledge Hiding: Knowledge hiding by individuals with in organizations presents cause for concern due to its impact on both organizations, and also its intended targets. Knowledge hiding, as defined by Connelly et al. (2012), is the process of intentionally not sharing information, data or knowledge by perpetrators within organizations with their intended targets. This phenomenon has also been defined as releasing insubstantial information, or important information only as andwhen required (Lin \& Huang, 2010).A review of available literature on the subject reveals that some of the drivers of knowledge hiding can be identified as:a lack of employee trust towards leaders and organizations; poor employee incentives; employee retaliation; employee insecurity; the intentional withholding of knowledge; and feelings of psychological ownership (Černe, Nerstad, Dysvik, \& Škerlavaj, 2014); (Peng, 2013); (Connelly, Zweig, Webster, \& Trougakos, 2012).Important to note, however, is that knowledge hiding is not influenced by only these factors.

In studies conducted by Černe et al. (2014), and Kilduff et al. (2010), on the antecedents for knowledge hiding in performance-based organizational cultures, their findings reveal the further drivers of knowledge hiding to be: a desire for competitive advantage over colleagues; obtaining maximum benefit from the withholding of knowledge; slavishly following the instructions of managers;a fear of being excluded;and also the possible negative effects on employee careers or work positions caused by the disclosure of knowledge. The issue of knowledge hiding behaviors remains prevalent within modern-day business environments, according to Connelly et al. (2012), who argue in a study survey conducted in the Unites States of America, that a substantial number of respondents admitted to having, at one time or another, engaged in such activities. Connelly et al.'s (2012) finding is supported by the result of a survey conducted by Peng (2013)in a working environment in China, which shows that 46 percent of respondents attested to having previously engaged in knowledge hiding. Thus, the influence of leadership on staff knowledge hiding, more importantly with regard to the practice of servant leadership, should be regarded as crucial, since it could well be used to assist in reducingacts of knowledge hiding within organizations.

Leadership: Leadership concerns the manner in which people are cared for by those leading them. There are many types of leadership theory, with diverse foci, although many of the attributes associated with the various leadership styles display similarities in both content and nature. Few differences exist, however, in what these leaders believe, and in their mission and vision, with some of them concentrating firston the overall mission of their organizations, towhich they then align their leadership style in guiding people, while others focus primarily on the feelings of the employees they manage, whichthey then align with the overall organizational vision.The primary motive of the various types of leaders remains to ensure that the people they manage are well-treated and mentored, and also given ample opportunity to develop in order to be effectiveincontributing to the overall goals of their organizations. Many authors discuss the servant leadership style of management with regard to how it can assist staff to be more open amongst themselves within organizations, andalso encourage themto share knowledge and information freely (Greenleaf, 1977); (Park, Yoon, Song, \& Kim, 2013); (Hess, 2013); (Northouse, 2015); (Iarocci, 2017).

Servant Leadership: Servant leadership theory, according toGreenleaf (1977), is embodied bythe type of leader concerned with the wellbeing of staff before their own. Servant leaderstend to relate more to people at grassroots level, and align employee wellbeing with the overall vision of organizations. Thus, a servant leader is someone who ensures that their staff is well cared forthrough a shared vision, and through trust and collaboration aimed at the achievement of the overall organizational mission. Yukl (1998), furthermore, mentions that because increased organizational success generally indicates greater responsibility in managing others, the possibility exists for the growth and development of staff through servant leadership, because such leaders do what is best for organizations and not themselves. In addition, they constantly 78 
engage with their followers to discuss their needs, and how these can best be met by assisting them appropriately. When trust is built, and there is mutual respect between managers and staff, employees generally feel more at liberty to communicate with their leaders concerning how they can also be served in various ways (Tufail et al., 2016).

Servant leadership has been practiced over the years in the USA, and its effects are proven to be positively related to enhanced organizational performance; for example, some Fortune 500 Companies, such as TD Industries, South West Airline and Synoves Financial, attest to having achieved success with its use over the years (McLaughlin, 2001). Moreover, servant leadership is concerned with community participation, where everyone is considered important, and where they are included in the decision-making processes of organizations without discrimination ("fear or favor"). Servant leadership has long been practiced in the African context, where it is referred to as "Ubuntu" (Mibigi \& Maree, 1995), and this principle can be seen to have worked effectively for the various communities practicing it. In a study conducted by Nelson (2003), who interviewed South African leaders, whilst using as a model the servant leadership theory of Patterson (2003), which focuses on how servant leaders perform within their organizations, and whether this impacts positively on the performance of staff and companies, it isarguedthat servant leadership can have a positive effect on the overall performance of organizations. Nelson regards this as being especially prevalent where those required to relate to customers are staff at various organizational levels, who also need to be cared for and motivated to deliver on their various commitments, and the achievement of this through the servant leadership style adopted is therefore emphasized (Nelson, 2003).

\section{Theoretical Framework- Servant Leadership and Knowledge Hiding}

Yukl (1998) describes leadership as "the process by which a person exerts influence over others and inspires, motivates and directs their activities to help achieve group or organizational goals". Moreover, he indicates that the influence effective leaders exert on their followers can lead to their increased performance, and the achievement of overall organizational goals. Effective leadership is also regarded as useful in assisting organizations to achieve competitive advantage, and improve on their ethical behavior and fair dealings with staff (Park, Yoon, Song, \& Kim, 2013); (Bass \& Riggio, 2006).The application of the servant leadership style creates opportunities for followers to excel in communal environments where they willingly serve the needs of others(Melrose, 1995). Similarly, because of nature of the service such leaders bestow, this results in earning their followers' trust (Lee \& Zemke, 1993),since they also strive to ensure that their followers grow both personally and professionally (Connelly, Zweig, Webster, \& Trougakos, 2003). Servant leaders possess the following attributes: the ability to serve (Turner, 2000); (Batten, 1997); (Greenleaf, 1977), (Pollard, 1997); listening skills; empathy; awareness; persuasion; conceptualization; foresight; stewardship; commitment to individual growth; and community building (Greenleaf, 1998).

Hence, servant leaders listen to their followers, encourage them, praise them, coach and mentor them, and also point them in the right direction when they deviate from the goals agreed upon (Blanchard, 1997). These leaders are constantly evaluating the work environment to ensure that their followers' needs are successfully beingmet; anddo not believe their staffneed to be micro-managed in order to perform, but rather that, bycreating the right values and culture, they will perform beyond the expectations set. Thus, with the right attitude and behavior from leaders, followers can be motivated to achieve higher work performance (Hess, 2013).Few empirical studies existon the relationship between servant leadership and knowledge hiding. As a result of the limited resources linking these two areas together, what literature is available suggests that the raising of both staff morale and ethical levels within organizations can effectively be achieved through servant leadership, whereby it is possible to ensure that all role-playersareincluded, without discrimination, during the decision-making process (Zeigler-Hill, Southard, Archer, \& Donohoe, 2013).Moreover, servant leaders care about the needs of their followers, and also exhibit trust; and these attributes exert a positive influence on the ability of followers to share knowledge without fear of recrimination, which can lead to the achievement of common goals through improved organizational performance (Russell \& Stone, 2002).

Contrarily, knowledge hiding does not encourage honesty, care for others, good ethical behavior or collaboration within organizations (Černe, Nerstad, Dysvik, \& Škerlavaj, 2014); (Peng, 2013); (Connelly, 
Zweig, Webster, \& Trougakos, 2012); (Lin \& Huang, 2010), and has a negative impact on both individual and organizational performances, and on the achievement of competitive advantage. Thus, it can be argued that servant leadersdonot encourage their followers to engage in knowledge hiding activities, which can hinder the progress and performance of organizations. As a result of the positive correlation between knowledge sharing and servant leadership, this style of leadership could thencebe used as a catalyst in assisting to reduce tendenciesamongst employeestowards knowledge hiding attitudes, and, in view of the foregoing empirical evidence from literature and theory, it is consequently hypothesized (H1) that: "Increased servant leadership in organizations will mitigate knowledge hiding".

Servant Leadership and Psychological Ownership of Knowledge: The psychological ownership of knowledge, according to Pickford (2016), is "the feeling of possession over a target, an object, concept, organization or other person that may or may not be supported by formal ownership". Theseauthors further postulate that the psychological ownership of knowledge refers toknowledge not only as an isolatedobject, but also involves its owners. Servant leaders are those who create opportunities for their followers to excel by encouraging trust, communal relationships, and good ethical behavior in order for them to achieve an organization's desired goals, and should also implement effective approaches for achieving the collective goals of both organizations and their employees (Northouse, 2015). Servant leaders bring meaning, prosperity and contentment to the workplace, which: enables a better customer experience; inspires greater innovation; instils trust in employees; and attracts the best available talent to organizations (Iarocci, 2017). In addition, the positive impact servant leadership areobserved to have on organizational performance could draw investors to those companies practicing this leadership style. While not much research has been carried out on the relationship between servant leadership and psychological ownership, the available literature suggests that servant leadership can havea positive overall impact on staff performance, since suchleadersenact trust, care for their followers, and empathize with and provide services for them, all of which in stills confidence by encouraging them to operate at their best (Hess, 2013).

Psychological ownership concerns the attitudes employees adopt towards the disclosure of information or data, and therefore also towardsknowledge sharing in order for them to remain competitive within organizations. Such attitudes can, however, lead to distrust and consequently hinder productivity (Černe, Nerstad, Dysvik, \& Škerlavaj, 2014); (Connelly, Zweig, Webster, \& Trougakos, 2012); (Peng, 2013); (Li, Yuan, Ning, \& Li-Ying, 2015). In a study conducted by Knipfer et al. (2015), the authors argue that any leader displaying negative behavior towards their followers there by engages in selfish attitudes; and that where leaders do not have the best interests of their employees at heart, this can result in encouraging knowledge hiding behavior within organizations. The effects of knowledge hiding behavior within organizations still lacks much in terms of empirical study, however, and it therefore remains an area in need of further research (Černe, Nerstad, Dysvik, \& Škerlavaj, 2014); (Connelly \& Kelloway, 2003); (Connelly, Zweig, Webster, \& Trougakos, 2012); (Peng, 2013); (Webster, et al., 2008). In performance-based organizations, there is a tendency for staff to engage in knowledge hiding in order for them to remain competitive (Kilduff, Elfenbein, \& Staw, 2010); (Černe, Nerstad, Dysvik, \& Škerlavaj, 2014). Employees thus engage in knowledge hiding due to issues associated with ownership, and tend to view knowledge as an asset requiring disproportionate protection, and are hence unwillingto lose it, which consequently prevents them from sharing it with others (Peng, 2013).

Pierce et al. (2003), in their study, indicate that psychological ownership sometimes becomes difficult to understand, since it exerts both positive and negative influences within organizations, which makes it problematic to determine when either effect is manifesting itself. The notion is supported inliterature (Jarvenpaa \& Staples, 2001); (Constant, Kiesler, \& Sproull, 1994) that psychological ownership has both a positive correlation with, and a negative effect on, knowledge sharing (Li, Yuan, Ning, \& Li-Ying, 2015), and can also exert a negative influence through encouraging knowledge hiding (Peng, 2013).Servant leadership is typifiedby leaderswho encourage individual and organizational performance, innovation, shared vision and trust, and who promote the achievement of the collective goals of organizations. Thus, as a result of the foregoing empirical evidence and theories, it is hypothesized (H2) that: "Higher levels of servant leadership will reduce psychological knowledge based ownership attitudes in an organization." 
Psychological Ownership of Knowledge as a Mediating Factor: Psychologically-based knowledge ownership, according to Pickford et al.(2016), is "the feeling of possession over a target, an object, concept, organization or other person, that may or may not be supported by formal ownership". Knowledge hiding is better explained by psychological ownership theory, since psychologically-based ownership develops in individuals due to: the time they invest in acquiring knowledge; the level of control they have on knowledge hiding targets; a fear of losing control of knowledge ownership; and also possible loss of competitive advantage over workplace rivals (Pierce, Kostova, \& Dirks, 2003). The inference can therefore bedrawn that psychological ownership alsohas a positive correlation with knowledge hiding. Staff with strong knowledge bases possess greater bargaining power within organizations, due to the relevance of their experience in helping companiesachieve theirgoals (Bacharach \& Lawler, 1980); thisallows them tomore easily dictate the level of remuneration they receive for performing work, and also assists them in being more influential within organizations.

Thus, employees tend to develop strong levels of knowledge-based psychological ownership arising from its associated attributes; although it may also be inferred that staff with strong knowledge-based psychological ownership probably engage in knowledge hiding more often than those with weaker knowledge-based psychological ownership. In a study conducted by Li et al.(2015), however, it is argued that psychological ownership couldfacilitate in improving the positive relationship between staff commitment and their willingness to freely share knowledge within organizations. Servant leaders can play a vital role ininfluencing the attitudes of their followers towards knowledge-based psychological ownership using, for example: an open and participatory managerial style (Doh, J. \& Quigley, N., 2014); profit-sharing; employee participation in decision-making; access to relevant information (Chi \& Han, 2008); ensuring employee job satisfaction (Ozler, Yilmaz, \& Ozler, 2008); and boosting of staff morale and productivity through strong leadership (Bernhard \& O'Driscoll, 2011). All of these initiatives can exercise a positive influence on employee attitudes towards psychological ownership. Hypothesized (H3) from the foregoing, therefore, is that: "Knowledgebased psychological ownership will mediate the servant leadership and knowledge hiding relationship".

\section{Conceptual Framework}

It is argued that staff with higher levels of psychological ownership are more likely to engage in knowledge hiding behaviors, whilst staff with lower psychological ownership levels will probably not partake in this activity to such a great degree, whichis in alignment with the findings of studies already conducted by various scholars (Černe, Nerstad, Dysvik, \& Škerlavaj, 2014); (Peng, 2013); (Connelly, Zweig, Webster, \& Trougakos, 2012); (Lin \& Huang, 2010).In addition, it is proposed that servant leadership canplay a vital role in ensuring that staff avoidengaging in knowledge hiding behaviors by: building trust within teams; encouraging collaboration; creating opportunities for employees to excel; communal relationships; and the promotion of good ethical staff behavior, whereby the desired goalsof both employees and organizations can be achieved. Proposed in this paper, therefore, and based on the literature reviewed and theories encountered, is a conceptual framework (Figure 1), which illustrates the mediating influence of knowledge-based psychological ownership on the servant leadership and knowledge hiding relationship. The primary motive of servant leaders is to ensure both the personal and professional development of employees in attempting to create more servant leaders amongst staff, rather than their simply remaining followers (Duhigg, 2016). 
Figure 1: Conceptual framework of the influence of servant leadership on knowledge hiding and the role of knowledge-based psychological ownership

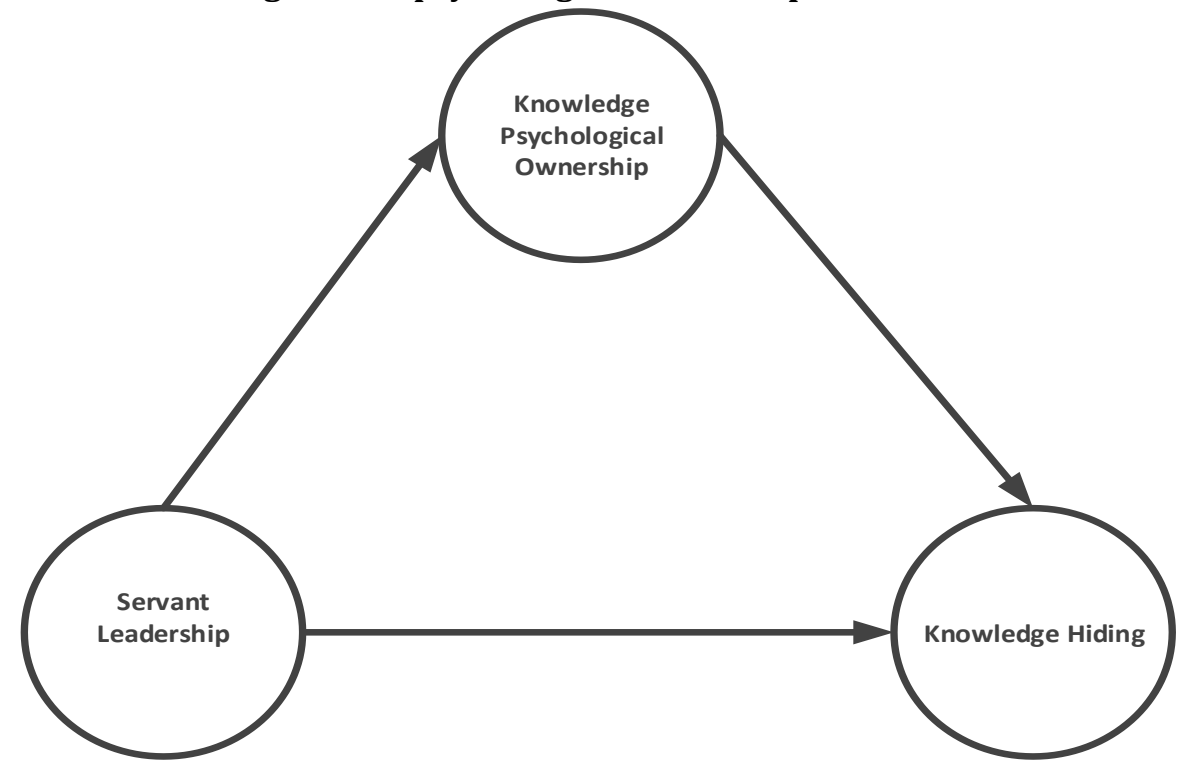

\section{Conclusion}

Based on the foregoing, this paper proposes a theoretical framework drawn fromboth the theoretical and empiricalevidenceavailable in literatureregarding the influence of servant leadership on knowledge hiding, and the mediating influenceexertedby psychological knowledge-basedownership. Once tested and validated, this framework is proposed as contributing to the knowledge management literature. The framework could, furthermore, assist in creating awareness concerning knowledge hiding and its impactonorganizations, especially where this is considered to havea negative effect on organizational performance.Utilization of theproposed modelcould, moreover,provide furtherinsightson the role played by servant leadership in minimizing knowledge hiding attitudes exhibited by staff, and on psychological knowledge-based ownership as a mediating factor in understanding how servant leadership can discourage staff knowledge hiding, and also be used to reduce its negative effects. The model could, in addition, assist managers to develop strategies for motivating staff to become more committed to achieving the vision of companies, in order to improve both their individual performance and that of organizations overall.

Furthermore, revealed is that staff with higher levels of psychological ownership are more likely to engage in knowledge hiding, whilst staff with lower psychological ownership levels probably do not partake as much in suchactivities. Servant leadership couldtherefore play a vital role, through building trust, collaboration, opportunity creation, and the promotion of good ethical behavior, to ensure that employees avoid engaging in knowledge hiding altogether. Although this paper remains limited to highlighting the primarily positive effects of servant leadership, and does not consider other possible leadership styles, future studies could also be conducted to test both the positive and negative influences of such styles, along with mediating instrumentsother thanthat of psychological ownershipdiscussed here.

\section{References}

Algere, L., Sengupta, K. \& Lapiedra, R. (2011). Knowledge management and innovation performance in a hightech SMEs industry. International Small Business Journal, 31(4), 454-470.

Bacharach, S.\& Lawler, E. (1980). Power and Politics in Organizations: The Social Psychology of Conflict, Coalitions, and Bargaining.San Francisco, CA: Jossey Bass.

Bass, B.\& Riggio, R. (2006).Transformational Leadership. Mahwah, NJ: Erlbaum.

Batten, J. (1997). Servant-leadership: a passion to serve. In L. C. Spears (Ed.), Insights on Leadership: Service, Stewardship, Spirit, and Servant-Leadership (pp. 38-53). New York, NY: John Wiley \& Sons. 
Bernhard, F.\& O'Driscoll, M. (2011). Psychological Ownership in Small Family-Owned Businesses: Leadership Style and Nonfamily-Employees' Work Attitudes and Behaviours. Group \& Organization Management, 36(3), 345-384.

Blanchard, K. (1997). Situational leadership. In K. Shelton (Ed.), A New Paradigm of Leadership: Visions of Excellence for 21st Century Organizations (pp. 149-153). USA, United States of America: Executive Excellence Publishing.

Business Dictionary. (2017). Business Dictionary. Retrieved from http://www.businessdictionary.com/defi nition/knowledge-management.html

Černe, M., Nerstad, C., Dysvik, A.\& Škerlavaj, M. (2014). What goes around comes around: Knowledge hiding, perceived motivational climate, and creativity. Academy of Management Journal, 57(1), 172-192.

Chi, N.\& Han, T. (2008). Exploring the Linkages between Formal Ownership and Psychological Ownership for the Organization: The Mediating Role of Organizational Justice. Journal of Occupational and Organizational Psychology, 81(4), 691-711.

Connelly, C.\& Kelloway, E. (2003). Predictors of employees' perceptions of knowledge sharing cultures. Leadership \& Organization Development Journal, 24(5), 294-301.

Connelly, C., Zweig, D., Webster, J.\& Trougakos, J. (2003). Predictors of employees' perceptions of knowledge sharing cultures. Leadership \& Organization Development Journal, 24(5), 294-301.

Connelly, C., Zweig, D., Webster, J.\& Trougakos, J. (2012). Knowledge hiding in organizations. Journal of Organizational Behaviour, 33(1), 64-88.

Constant, D., Kiesler, S.\& Sproull, L. (1994). What's mine is ours, or is it? A study of attitudes about information sharing. Information Systems Research, 5(4), 400-421.

Davenport, T. \& Prusak, L. (1998). Working Knowledge. Boston, MA: Harvard Business School Press.

Doh, J. \& Quigley, N. (2014). Responsible Leadership and Stakeholder Management: Influence Pathways and Organizational Outcomes. Academy of Management Perspectives, 28(3), 255-274.

Duhigg, C. (2016). What Google Learned from Its Quest to Build the Perfect Team. The New York Times. The New York Times.

Emadzade, M., Mashayekhi, B.\& Abdar, E. (2012). Knowledge management capabilities and organizational performance. Journal of Contemporary Research in Business, 3(11), 781-790.

Greenleaf, R. K. (1977). Servant Leadership: A Journey into the Nature of Legitimate Power and Greatness. New York: Paulist Press.

Greenleaf, R. K. (1998).The Power of Servant-Leadership : Essays by Robert K. Greenleaf. (L. C. Spears, Ed.) San Francisco, CA: Berrett-Koehler Publishers.

Hess, E. D. (2013). Servant leadership: A path to high performance. The Washington Post.

Iarocci, J. J. (2017). Servant Leadership in the Workplace: A Brief Introduction. Retrieved from Cairnway Center for Servant Leadership Excellence. Atlanta, Georgia, United States of America: Cairnway Center for Servant Leadership Excellence LLC. Retrieved from https://serveleadnow.com/ebook

Jarvenpaa, S.\& Staples, D. (2001). Exploring Perceptions of Organizational Ownership of Information and Expertise. Journal of Management Information Systems, 18(1), 151-183.

Kilduff, G., Elfenbein, H.\& Staw, B. (2010). The psychology of rivalry: A relationally dependent analysis of competition. Academy of Management Journal, 53(5), 943-969.

Knipfer, K., Schmid, E., Mangold, S.\& Melzer, K. (2015). If you take it all - I hide it! The effects of exploitative leadership on followers' knowledge hiding within the team: A mediation model of distrust. Symposium for the Convention of the Industrial \& Organizational Psychology. Mainz.

Lee, C.\& Zemke, R. (1993). The search for spirit in the workplace. Training, 30(6), 21-35.

Li, J., Yuan, L., Ning, L.\& Li-Ying, J. (2015). Knowledge Sharing and Affective Commitment: The Mediating Role of Psychological Ownership. Journal of Knowledge Management, 19(6), 1146-1166.

Liang, T., You, J.\& Liu, C. (2010). A resource-based perspective on information technology and firm performance: a meta-analysis. Industrial Management and Data Systems, 110(8), 1138-1158.

Lin, T.\& Huang, C. (2010). Withholding effort in knowledge contribution: the role of social exchange and social cognitive on project teams. Information and Management, 47(3), 188-196.

McLaughlin, K. (2001). A strong foundation. Training, 38(3), 84.

Melrose, K. (1995). Making the Grass Greener on Your Side: A CEO's Journey to Leading by Service. San Francisco, CA: Berrett-Koehler Publishers. 
Mibigi, L.\& Maree, J. (1995). Ubuntu: The Spirit of African Transformation Management. Johannesburg: Knowledge Resources.

Nelson, L. (2003). An exploratory study of the application and acceptance of servant-leadership theory among black leaders in South Africa. PhD Dissertation. Regent University.

Northouse, P. G. (2015). Leadership: Theory and Practice, 7th Ed. Los Angeles: Sage.

Ozler, H., Yilmaz, A.\& Ozler, A. (2008). Psychological Ownership: An Empirical Study on its Antecedents and Impacts upon Organizational Behaviours. Problems and Perspectives in Management, 6(3), 38-47.

Park, C., Yoon, S., Song, J.\& Kim, J. (2013). A missing link: Psychological ownership as a mediator between transformational leadership and citizenship behaviour. Human Resources Development International, 16(5), 37-41.

Patterson. (2003). Servant leadership theory: A theoretical definition and a presentation of the virtues of the servant leader including love, humility, altruism, vision, trust, empowerment and service. Doctoral dissertation. Regent University, Virginia Beach, Virginia, United States of America.

Peng, H. (2013). Why and When Do People Hide Knowledge? Journal of Knowledge Management, 17(3), 398415.

Pickford, H. C., Joy, G. \& Roll, K. (2016). Psychological ownership effects and application. Mutuality in Business Briefing No. 2. Retrieved November 20, 2017, from https://ssrn.com

Pierce, J., Kostova, T.\& Dirks, K. (2003). The state of psychological ownership: Integrating and extending a century of research. Review of General Psychology, 7(1), 84-107.

Pollard, W. C. (1997). The leader who serves. Strategy and Leadership, 25(5), 49-51.

Russell, R.\& Stone, A. (2002). A review of servant leadership attributes: Developing a practical model. Leadership \& Organization Development Journal, 23(3), 145-157.

Tufail, M. S., Muneer, S. \& Ishtiaq, M. (2016). Job Characteristics with Task and Contextual Performance: Moderating Role of Procedural Justice for Front Line Managers. Journal of Social Sciences, Special Issue, 299-508

Turner, W. B. (2000). The Leadership of Love: A Journey Towards Servant Leadership. Macon, GA: Smuth and Helwys Publishing.

Webster, J., Brown, G., Zweig, D., Connelly, C., Brodt, S.\& Sitkin, S. (2008). Beyond knowledge sharing: Withholding knowledge at work. Research in Personnel and Human Resources Management, 27, 1-37.

Yukl, G. (1998). Leadership in Organisations, 4th Ed. Upper Saddle River, NJ: Prentice-Hall.

Zeigler-Hill, V., Southard, A., Archer, L.\& Donohoe, P. (2013). Neuroticism and negative affect influence the reluctance to engage in destructive obedience in the milgram paradigm. Journal of Social Psychology, 153(2), 161-174. 